\title{
Synthesis and Characterization of Star-Shaped Block Copolymer sPCL-b-PEG-GA
}

\author{
Yi Zhang, ${ }^{1}$ Qian Zhao, ${ }^{2}$ Hewei Shao, ${ }^{2}$ Shiyu Zhang, ${ }^{2}$ and Xiaoyan Han ${ }^{2}$ \\ ${ }^{1}$ Department of Experimental Teaching, Tianjin University of Traditional Chinese Medicine, Tianjin 300193, China \\ ${ }^{2}$ Tianjin Key Laboratory of Chemistry and Analysis of Chinese Materia Medica, School of Chinese Materia Medica, \\ Tianjin University of Traditional Chinese Medicine, Tianjin 300193, China \\ Correspondence should be addressed to Xiaoyan Han; 15022611743@163.com
}

Received 28 February 2014; Revised 28 March 2014; Accepted 31 March 2014; Published 27 April 2014

Academic Editor: George Z. Kyzas

Copyright (C) 2014 Yi Zhang et al. This is an open access article distributed under the Creative Commons Attribution License, which permits unrestricted use, distribution, and reproduction in any medium, provided the original work is properly cited.

Compared to linear polymers with the same molecular weight, star-shaped polymers have the superiority of drug loading and delivery. The glycyrrhetinic acid (GA) from licorice is remarkably characteristic of liver distribution and liver cells targetability. In this paper, four-armed star-shaped polycaprolactone was synthesized and amino polyethylene glycol was modified by glycyrrhetinic acid $\left(\mathrm{NH}_{2}\right.$-PEG-GA). Then the condensation reaction between the two above polymers finally produced four-armed star-shaped poly(ethylene glycol)-b-poly( $\varepsilon$-caprolactone) block copolymer (sPCL-b-PEG-GA). The structures of the intermediates and product were characterized by ${ }^{1} \mathrm{H}$ NMR. The results indicated that the structure and molecular weight of sPCL-b-PEG-GA can be controlled by the varied ratios of pentaerythritol (PTOL) to $\varepsilon$-caprolactone $(\varepsilon-\mathrm{CL})$ in the presence of stannous octoate $\left(\mathrm{Sn}(\mathrm{Oct})_{2}\right)$, and the amphiphilic copolymer sPCL-b-PEG-GA consists of PTOL as core, PCL as inner hydrophobic segments, PEG as external hydrophilic segments, and terminal glycyrrhetic acid as targeting ligand. The work explored a new synthesis route of star poly(ethylene glycol)-b-poly( $\varepsilon$-caprolactone) copolymer with liver targetability. The star-shaped polymer is expected to be an efficient drug carrier.

\section{Introduction}

Polycaprolactone (PCL) has good biocompatibility, nontoxicity, and biodegradability, so it has been widely studied and applied in the field of biomedicine and drug controlled release, and so forth $[1,2]$. However, PCL also has strong hydrophobicity, which impeded its application in biological and pharmaceutical areas. The amphiphilic block copolymer of PCL modified by polyethylene glycol (PEG) could enhance the hydrophilicity of PCL, prevent protein adsorption, evade the recognition and phagocytosis of the reticuloendothelial system, and easily go through physiological barrier, which has become currently the focus of the nanopharmaceutical research [3-5].

In recent years, there has been an increasing interest in star-shaped polymers, which are branched polymers distinguished by a structure containing three or more linear arms radiating from a center. Literatures [6-8] reported that compared to linear polymers with the same molecular weight, the star polymers have the superior properties, such as smaller hydrodynamic volume and lower viscosity, which was beneficial to drug loading and delivery.

Targeted drug delivery systems have emerged as a hot research topic in recent years. Targeting ligands can be specifically recognized by the receptor present on the desired site. The active ingredient glycyrrhetinic acid (GA) from licorice has excellent liver protection and detoxification and can promote the apoptosis of cancer cells. Moreover, it is also remarkably characteristic of liver distribution and liver cells targetability, which are confirmed by many scientists, such as Mao et al. [9] and He et al. [10].

In this study, we combined the advantages of star polymers as drug carrier and glycyrrhetinic acid with liver targetability to synthesize a novel and efficient starshaped polymer drug carrier for liver targeting. Meanwhile we present a highly efficient route to the synthesis of the glycyrrhetinic acid-modified star poly(ethylene glycol)b-poly( $\varepsilon$-caprolactone) polymer (sPCL-b-PEG-GA), whose structure was characterized by ${ }^{1} \mathrm{H}-\mathrm{NMR}$. 


\section{Experimental}

2.1. Materials. Glycyrrhetinic acid (purity 99\%) was purchased from Fujie Pharmaceutical Co., Ltd. (Xi'an, China); stannous octoate and caprolactone were purchased by Sigma Corporation; succinic anhydride, tosyl chloride, and polyethylene glycol (4000) were purchased from Tianjin Guangfu Chemical Institute; 4-dimethylaminopyridine, Nhydroxysuccinimide, and $\mathrm{N}, \mathrm{N}^{\prime}$-dicyclohexyl carbodiimide were purchased from GL Biochem (Shanghai) Ltd.

2.2. Synthesis of $\mathrm{NH}_{2}-\mathrm{PEG}-\mathrm{NH}_{2}$. PEG 4000 (20 g, $\left.5 \mathrm{mmol}\right)$

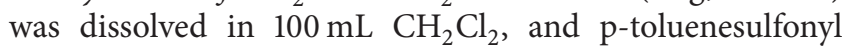
chloride $(\mathrm{TsCl})(3.81 \mathrm{~g}, 20 \mathrm{mmol})$ and $28 \mathrm{~mL}$ triethylamine were added to the above solution under continuous stirring. The mixture reacted for $12 \mathrm{~h}$ at room temperature.

When the reaction finished, reactive solution was neutralized with $1 \mathrm{~mol} / \mathrm{L} \mathrm{HCl}$. Excess anhydrous sodium carbonate was added to the separated organic phase. After stirring and filtering, the concentrated filtrate was dropped into excess cold anhydrous ether. The white precipitation was obtained, vacuum dried at $40^{\circ} \mathrm{C}$ until a constant weight, which was tosylation polyethylene glycol (sTO-PEG-OTs).

sTO-PEG-OTs $(23.19,10.0 \mathrm{mmol})$ and $80 \mathrm{~mL}$ ammonia were added into a $150 \mathrm{~mL}$ high pressure reactor and reacted for $6 \mathrm{~h}$ at $140^{\circ} \mathrm{C}$. After cooling to the room temperature, dichloromethane was used to extract aqueous phase. $100 \mathrm{~L}$ $(1 \mathrm{~mol} / \mathrm{L})$ sodium hydroxide solution was added in the combined organic phase and then stirred for 4 hours. The organic phase was washed by saturated salt water until $\mathrm{pH}$ was 7 . The solution was dried by anhydrous sodium sulfate for 12 hours. Finally, the white solid was obtained by filtering and concentrating, whose structure was confirmed by ${ }^{1} \mathrm{H}$ NMR.

2.3. Synthesis of $\mathrm{NH}_{2}-\mathrm{PEG}-\mathrm{GA}$. GA $(0.4707 \mathrm{~g}, 1 \mathrm{mmol}), \mathrm{EDC}$ $(0.7668 \mathrm{~g}, 4 \mathrm{mmol})$, NHS $(0.4604 \mathrm{~g}, 4 \mathrm{mmol})$, and triethylamine $(8 \mathrm{~mL}, 4 \mathrm{mmol})$ were mixed in $100 \mathrm{~mL} \mathrm{CH}_{2} \mathrm{Cl}_{2}$ and reacted for $5 \mathrm{~h}$ at room temperature. Then, the reaction solution was dropped slowly into $\mathrm{NH}_{2}-\mathrm{PEG}-\mathrm{NH}_{2}(2 \mathrm{~g}, 0.5 \mathrm{moL})$ solution in $30 \mathrm{~mL} \mathrm{CH}_{2} \mathrm{Cl}_{2}$ and reacted for $24 \mathrm{~h}$. The solution was concentrated under reducing pressure and precipitated with cold ether. Finally, the solid product of $\mathrm{NH}_{2}$-PEG-GA was obtained by filtration and vacuum drying. The structure of product was characterized by ${ }^{1} \mathrm{H}-\mathrm{NMR}$.

\subsection{Synthesis of Star PCL Terminated with Hydroxyl Group.} A certain proportion of caprolactone (CL) $(20 \mathrm{~mL})$, pentaerythritol (PTOL) $(0.1225 \mathrm{~g}, 0.0009 \mathrm{moL})$, and $\mathrm{Sn}(\mathrm{Oct})_{2}$ $(0.058 \mathrm{~mL})$ was added into dichloromethane solution in a sealed tube for melt polycondensation. The tube was repeatedly pumped vacuum and ventilated with nitrogen. The reaction was carried out at $60^{\circ} \mathrm{C}$ for $24 \mathrm{~h}$. The mixture in the sealed tube dissolved in dichloromethane after the reaction finished and precipitated and purified twice with anhydrous methanol. Finally, the product (sPCL-OH) was dried under vacuum, whose molecular weight can be controlled by the ratio of initiator/monomer.
2.5. Synthesis of PCL Terminated with Carboxyl Group. Succinic anhydride (6.0 mg, $0.12 \mathrm{mmol})$, DMAP (7.3 mg, $0.12 \mathrm{mmol})$, and triethylamine $(0.008 \mathrm{~mL}, 0.12 \mathrm{mmol})$ were added into 1,4-dioxane solution containing $0.04 \mathrm{mmol}$ sPCL$\mathrm{OH}$ and reacted for $24 \mathrm{~h}$ at room temperature under continuous stirring. The solvent was removed after the reaction finished. Then the concentrated solution was hydrolyzed in hot water and extracted three times with dichloromethane. Finally, the sPCL-COOH was obtained by methanol recrystallizing and vacuum drying.

2.6. Condensation of sPCL-COOH and $\mathrm{NH}_{2}-\mathrm{PEG}-\mathrm{GA}$. DCC (0.2 mmol, $0.0413 \mathrm{~g})$, NHS (0.2 mmol, 0.0232), and triethylamine $(0.1 \mathrm{~mL}, 0.2 \mathrm{mmol})$ were added to $30 \mathrm{~mL} \cdot \mathrm{CH}_{2} \mathrm{Cl}_{2}$ solution (containing $1 \mathrm{~g}$ PCL-COOH). The mixture reaction was carried out for $16 \mathrm{~h}$ under $\mathrm{N}_{2}$ atmosphere at room temperature. The reactant solution was filtered. Then GA-PEG$\mathrm{NH}_{2}$ was added to the above solution. After $24 \mathrm{~h}$ reaction, the reaction solution was transferred to dialysis bags (MWCO, 10000) and dialyzed for two days. Finally, the sPCL-b-PEGGA was obtained by freeze drying. Its structure and molecule weight were further characterized by ${ }^{1} \mathrm{H}$ NMR and GPC.

\subsection{Measurements}

2.7.1. ${ }^{1} H$ NMR Characterization. ${ }^{1} \mathrm{H}$ NMR spectroscopy was performed on a blucker 500 spectrometer. Tetramethylsilane was used as an internal standard.

2.7.2. UV Test. UV-vis absorption spectrum of the samples was recorded at room temperature using a Shimadzu 2401 UV-vis spectrophotometer (Dao jin).

2.7.3. GPC Test. The average molecular weight $\left(M_{W}\right)$ of the polymers was determined with a Waters 510 gel permeation chromatography with HPLC grade THF as the solvent and polystyrene as the standard. Specimen concentrations were $2.5-5 \mathrm{mg} / \mathrm{mL}$, and the flow rate was $1 \mathrm{~mL} / \mathrm{min}$ at $30^{\circ} \mathrm{C}$.

\section{Results and Discussion}

3.1. Characterization of $\mathrm{NH}_{2}-\mathrm{PEG}-\mathrm{GA}$ and Intermediate Products. In this study, $\mathrm{NH}_{2}-\mathrm{PEG}-\mathrm{NH}_{2}$ was synthesized and $\mathrm{NH}_{2}$-PEG- $\mathrm{NH}_{2}$ was further modified by GA. Schemes 1 and 2 showed the synthetic route of $\mathrm{NH}_{2}-\mathrm{PEG}-\mathrm{NH}_{2}$ and $\mathrm{NH}_{2}$-PEG-GA, respectively. Their structures were confirmed by ${ }^{1} \mathrm{HNMR}$. As was shown in Figure 1, compared with the original PEG (Figure 1(a)), the shift of $2.86 \mathrm{ppm}$ (peak b) which appears in Figure 1(b) is the chemical shift of methylene protons which linked with amino group. And the $3.65 \mathrm{ppm}$ (peak d) is the chemical shift of the proton from oxyethylene chain. Compared with Figures 1(b) and 1(d), the angular methyl, methyl, and methylene proton peaks of GA appear at $0.6 \mathrm{ppm} \sim 1.9 \mathrm{ppm}$ in Figure 1(c). Therefore, $\mathrm{NH}_{2}$ PEG-GA was synthesized successfully.

Figure 2 showed the UV spectrum of $\mathrm{NH}_{2}$-PEG-GA in methanol. The methanol solution of GA has a characteristic absorption peak at $246 \mathrm{~nm}$, and the solution of 


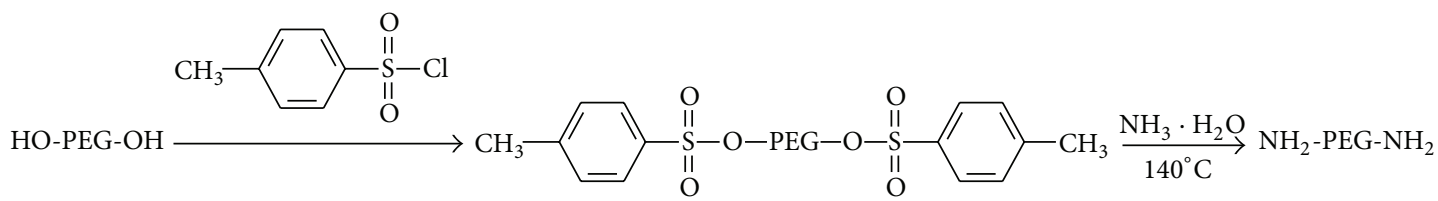

SCHEME 1: Synthesis of $\mathrm{NH}_{2}-\mathrm{PEG}-\mathrm{NH}_{2}$.

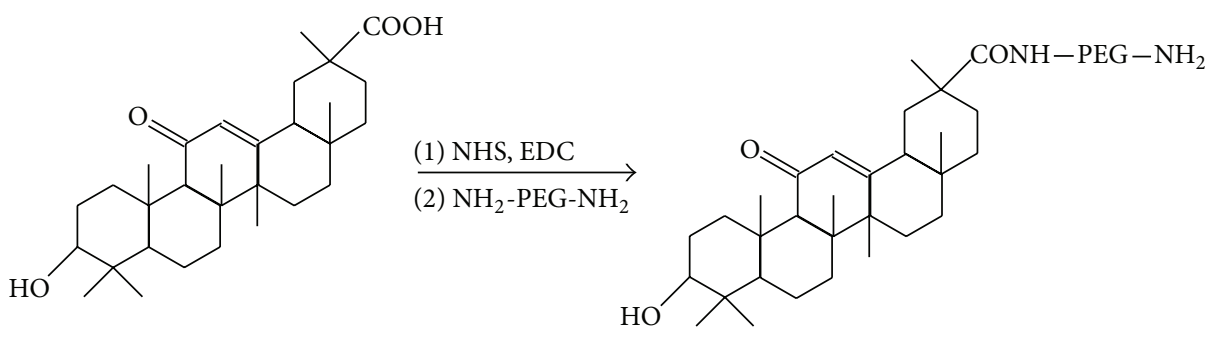

Scheme 2: Synthesis of $\mathrm{NH}_{2}$-PEG-GA.

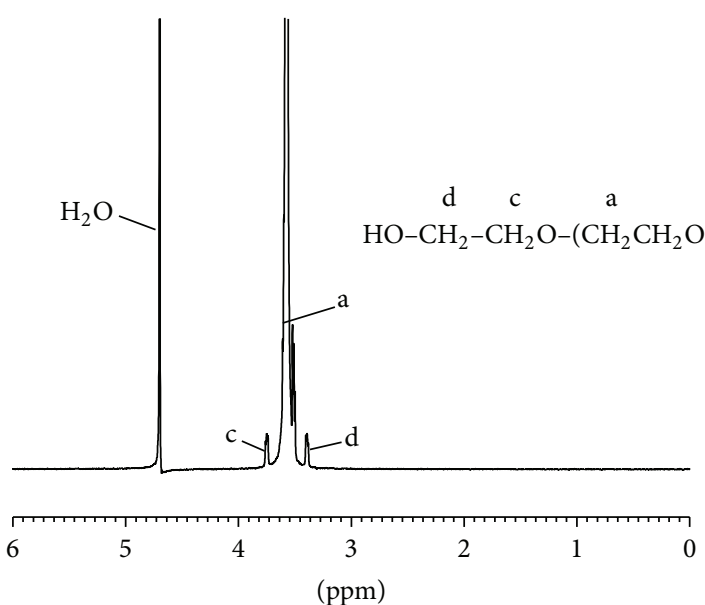

(a) PEG $\left(\mathrm{D}_{2} \mathrm{O}\right)$

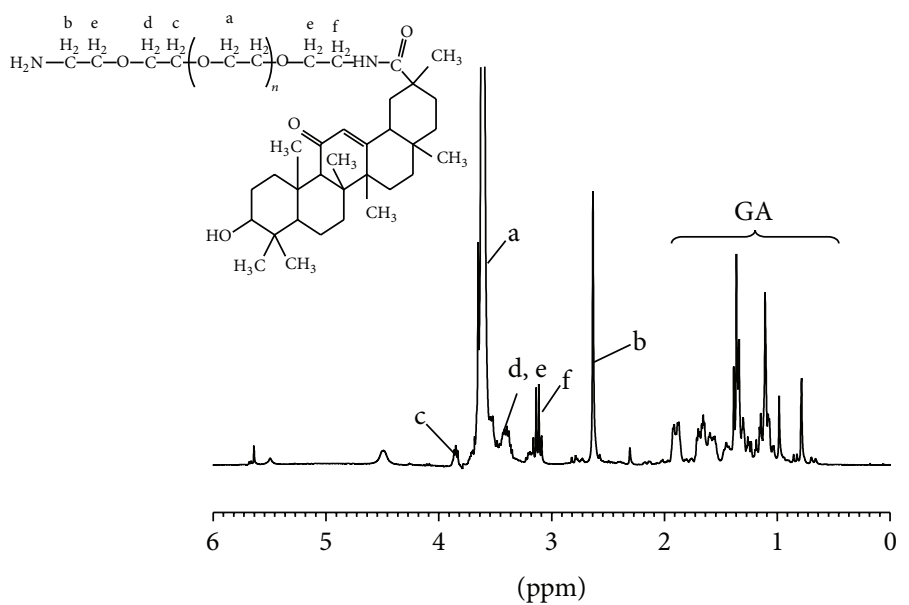

(c) GA-PEG- $\mathrm{NH}_{2}\left(\mathrm{CDCl}_{3}\right)$

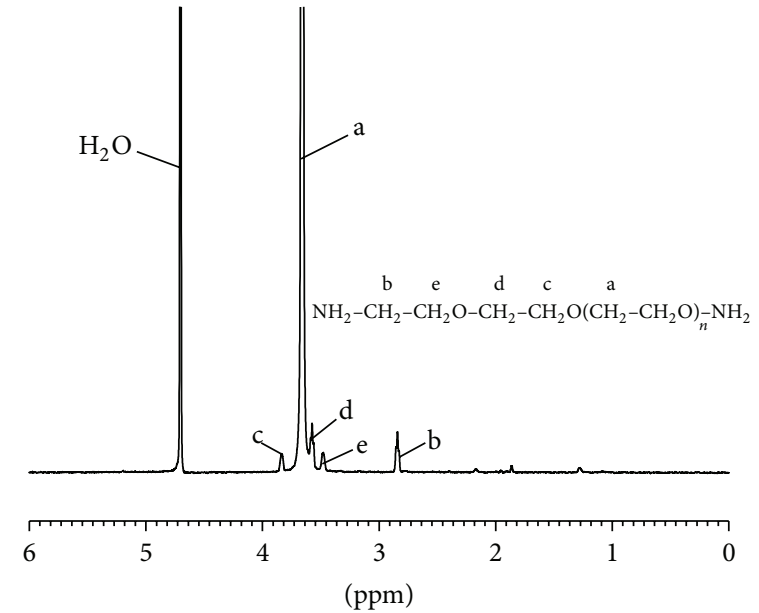

(b) $\mathrm{NH}_{2}$-PEG-NH $\mathrm{N}_{2}\left(\mathrm{D}_{2} \mathrm{O}\right)$

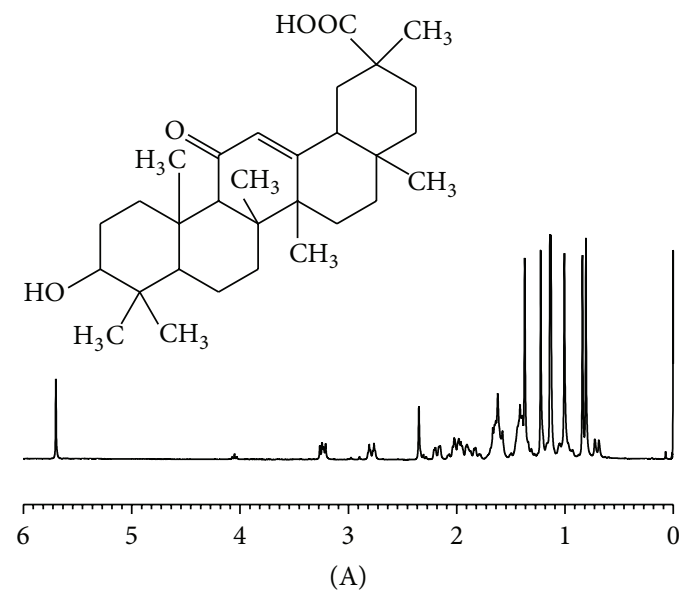

(d) $\mathrm{GA}\left(\mathrm{CDCl}_{3}\right)$

Figure 1: $\mathrm{H}^{1} \mathrm{NMR}$ spectrum of PEG $\left(\mathrm{A}, \mathrm{D}_{2} \mathrm{O}\right), \mathrm{NH}_{2}$-PEG-NH$\left(\mathrm{B}, \mathrm{D}_{2} \mathrm{O}\right), \mathrm{GA}-\mathrm{PEG}-\mathrm{NH}_{2}\left(\mathrm{C}, \mathrm{CDCl}_{3}\right)$, and GA $\left(\mathrm{D}, \mathrm{CDCl}{ }_{3}\right)$. 

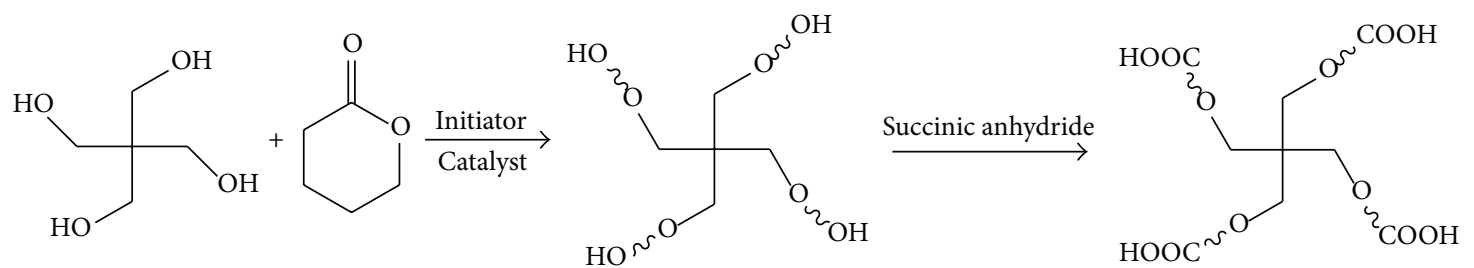

SCHeme 3: The synthesis route of star PCL-COOH.

sPCL-COOH $\underset{\left(\text { (2) } \mathrm{NH}_{2} \text {-PEG-GA }\right.}{\longrightarrow}$ sPCL-PEG-GA

SCHEME 4: Synthesis scheme of sPCL-b-PEG-GA copolymer.

TABLE 1: Material proportion of synthesized $\mathrm{SPCL}_{x}-\mathrm{OH}$.

\begin{tabular}{lcc}
\hline Copolymer & $\begin{array}{c}n \text { (monomer) }: n \\
\text { (initiator) }\end{array}$ & $\begin{array}{c}n \text { (monomer) }: n \\
\text { (catalyst) }\end{array}$ \\
\hline $\mathrm{sPCL}_{50}$ & $50: 1$ & $10000: 1$ \\
$\mathrm{sPCL}_{100}$ & $100: 1$ & $10000: 1$ \\
$\mathrm{sPCL}_{200}$ & $200: 1$ & $10000: 1$ \\
\hline
\end{tabular}

$\mathrm{NH}_{2}$-PEG- $\mathrm{NH}_{2}$ without coupling GA has no absorption between $200 \mathrm{~nm}$ and $300 \mathrm{~nm}$. Since the methanol solution of $\mathrm{NH}_{2}$-PEG-GA has an obvious characteristic absorption peak at $250 \mathrm{~nm}$, the modification $\mathrm{NH}_{2}-\mathrm{PEG}-\mathrm{NH}_{2}$ by GA was furtherly proved to be successful.

3.2. Characterization of $s P C L-C O O H, s P C L-b-P E G-G A$, and Intermediate Products. Schemes 3 and 4 show the syntheses process of sPCL-COOH and sPCL-b-PEG-GA, respectively. First, sPCL-OH was synthesized by ring-opening polymerization of $\varepsilon$-CL using the PTOL as initiator. Second, the sPCL$\mathrm{OH}$ was further activated with succinic anhydride to yield the sPCL-COOH, and then $\mathrm{NH}_{2}$-PEG-GA was conjugated to the sPCL-COOH to produce sPCL-b-PEG-GA.

The different molecular weight $\mathrm{SPCL}_{x}-\mathrm{OH}$ was synthesized by varied molar ratios of $\varepsilon$-CL/PTOL in the ringopening reaction (labeled as $\mathrm{sPCL} \mathrm{P}_{50}, \mathrm{sPCL}_{100}$, and $\mathrm{sPCL} \mathrm{PL}_{200}$, respectively). The synthesis parameters of $\mathrm{sCL}_{x}-\mathrm{OH}$ was shown Table 1.

The structure of sPCL-OH, sPCL-COOH, and sPCLPEG-GA was confirmed by ${ }^{1} \mathrm{H}$ NMR. Figure 3 (a) showed the ${ }^{1} \mathrm{H}$ NMR spectrum of sPCL-OH. Chemical shifts at 1.4 1.6 (peak c and peak d), 2.4 (peak b), and 4.1 ppm (peak e) can be assigned to the signal of independent methylene protons, carbonyl group adjacent to methylene protons, and oxygen atoms in acyloxy group adjacent to methylene protons in PCL unit, respectively. When SPCL-OH reacted with succinic anhydride, as was shown in Figure 3(b), a new chemical shift of $\mathrm{CH}_{2}$ appears at $\delta=2.6$, which indicates that PCL terminated with carboxylic group (sPCL-COOH) was produced by the reaction of sPCL-OH with succinic anhydride. Compared with Figure 3(b) and Figure 1(c), Figure 3(c) revealed that not only characteristic peak of PCL (1.4 1.6, 2.4 and 4.1 ppm)

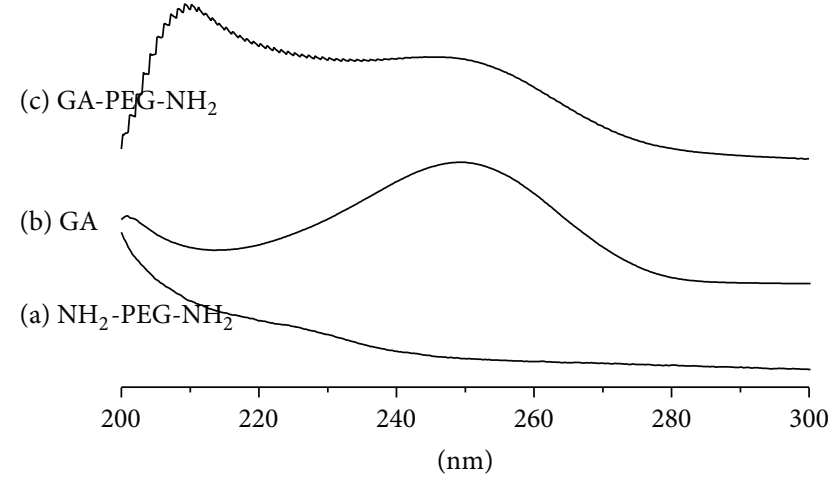

Figure 2: UV spectrum of $\mathrm{NH}_{2}$-PEG- $\mathrm{NH}_{2}\left(\mathrm{H}_{2} \mathrm{O}\right)$, GA $\left(\mathrm{CH}_{3} \mathrm{OH}\right)$, and $\mathrm{NH}_{2}$-PEG-GA $\left(\mathrm{CH}_{3} \mathrm{OH}\right)$.

TABLE 2: Number-average molar mass $\left(M_{n}\right)$, weight-average molecular weight $\left(M_{w}\right)$ and of $\mathrm{sPCL}_{x}$, and $\mathrm{sPCL}_{x}-\mathrm{PEG}-\mathrm{GA}$.

\begin{tabular}{|c|c|c|c|}
\hline Sample & $M_{n}$ (Dalton) & $M_{w}$ (Dalton) & PDI \\
\hline $4 \mathrm{~s}-\mathrm{PCL}_{50}$ & 9520 & 11019 & 1.15 \\
\hline $4 s-\mathrm{PCL}_{100}$ & 12985 & 14975 & 1.15 \\
\hline $4 s-\mathrm{PCL}_{200}$ & 16890 & 22834 & 1.35 \\
\hline $4 \mathrm{~s}-\mathrm{PCL}_{50}$-PEG-GA & 24075 & 28890 & 1.20 \\
\hline $4 s-P_{100}-P E G-G A$ & 27502 & 31398 & 1.14 \\
\hline $4 \mathrm{~s}-\mathrm{PCL}_{200}-\mathrm{PEG}-\mathrm{GA}$ & 36164 & 45566 & 1.26 \\
\hline
\end{tabular}

but also that of $\mathrm{NH}_{2}$-PEG-GA $(3.65,0.6-1.9 \mathrm{ppm})$ appeared, which confirmed the chemical structure of sPCL-g-PEG-GA.

Table 2 showed the molecular weight and their distribution by GPC for the $\mathrm{sPCL}_{x}-\mathrm{OH}$ and $\mathrm{sPCL}_{x}-\mathrm{PEG}-\mathrm{NH}_{2}$. The sPCL-g-PEG-GA containing different PCL block molecular weights were generated by altering the molar ratio of $\varepsilon$-CL/PTOL in the reaction solution. The formation of amphiphilic copolymers was shown by the increase of $\mathrm{Mn}$ of $\mathrm{SPCL}_{x}$-PEG-GA compared with the corresponding $\mathrm{SCL}_{x^{-}}$ $\mathrm{OH}$ by GPC. The molecular weights of $\mathrm{PPCL}_{50 x}-\mathrm{OH}, \mathrm{sPCL}_{100^{-}}$ $\mathrm{OH}$, and $\mathrm{sPCL}_{200}-\mathrm{OH}$ were 9520,12985 , and 16890 Dalton, respectively. The molecular weight of $\mathrm{sPCL}_{x}$-PEG-GA was close to the sum of the $\mathrm{SPCL}_{x}-\mathrm{OH}$ 's molecular weight and PEG chain's molecular weight from four arms, which further confirmed the branched structure of polymers.

\section{Conclusion}

$\mathrm{NH}_{2}$-PEG-GA and sPCL-COOH were synthesized successfully in this work. Finally, sPCL-PEG-GA was prepared by 


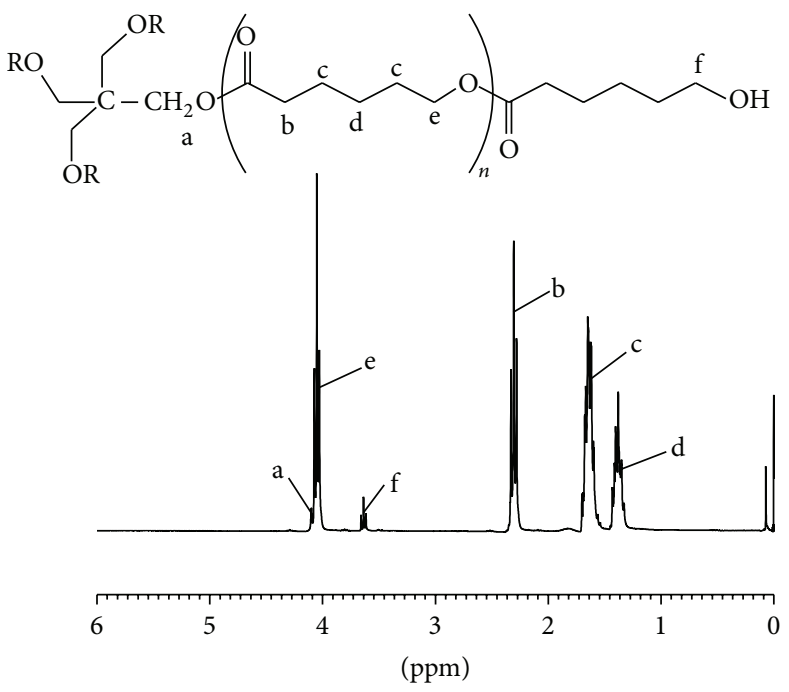

(a) sPCL-OH $\left(\mathrm{CDCl}_{3}\right)$

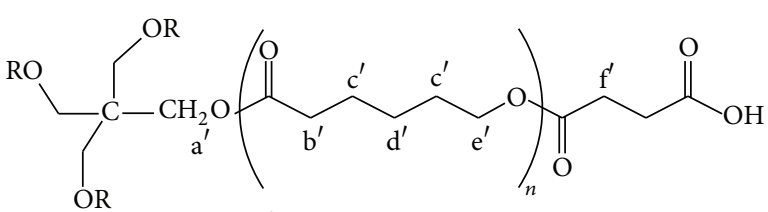
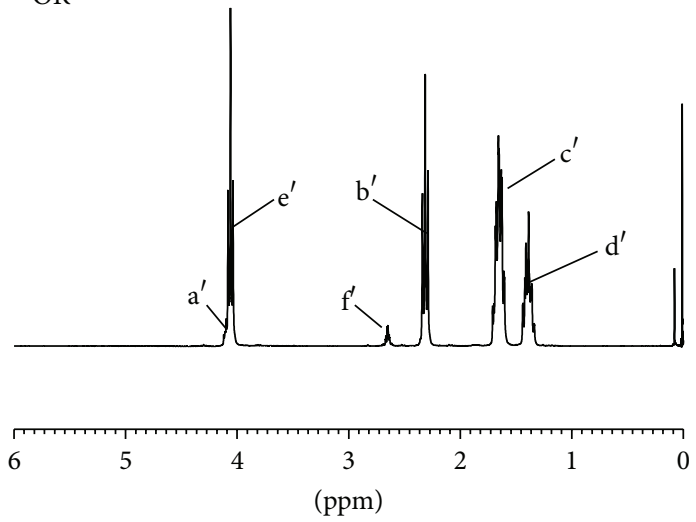

(b) sPCL-COOH $\left(\mathrm{CDCl}_{3}\right)$

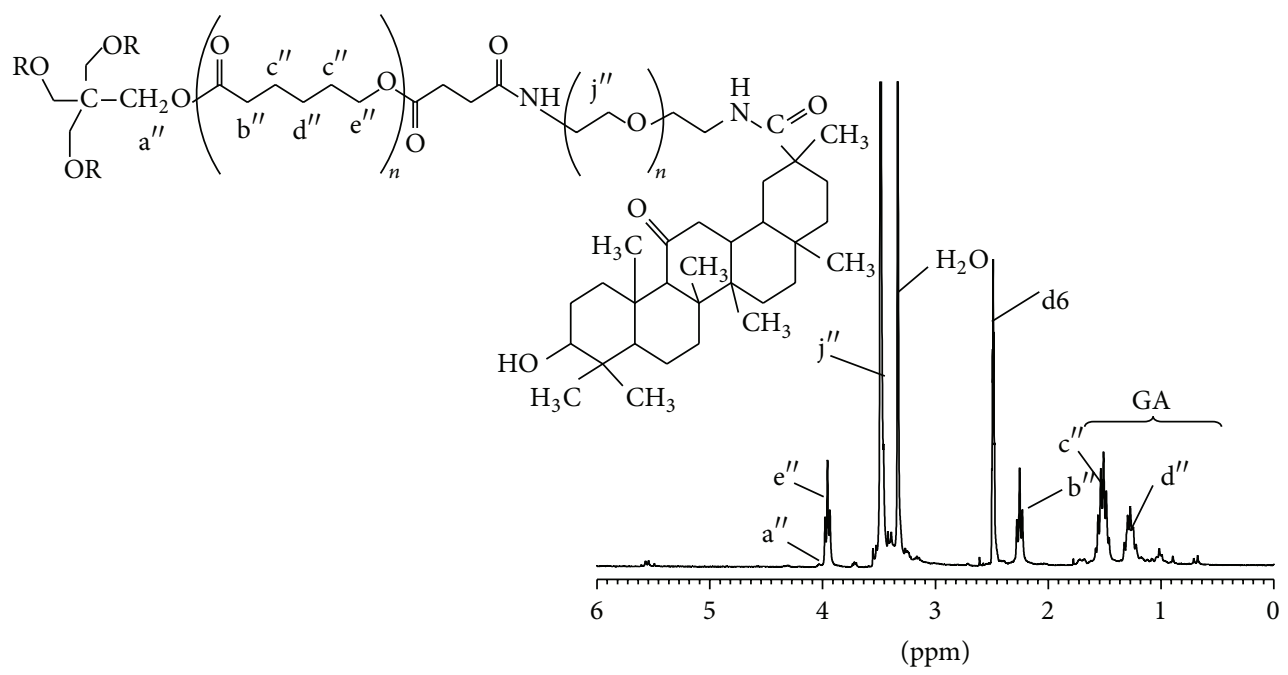

(c) $\mathrm{sPCL}-\mathrm{NH}_{2}$-PEG-GA (DMSO)

Figure 3: $\mathrm{H}^{1} \mathrm{NMR}$ spectrum of sPCL-OH ( $\left.\mathrm{A}, \mathrm{CDCl}_{3}\right)$, sPCL-COOH (B, $\left.\mathrm{CDCl}_{3}\right)$, and sPCL-g-PEG-GA (C, DMSO).

a coupling reaction between amino and carboxyl groups in the $\mathrm{NH}_{2}$-PEG-GA and sPCL-COOH, respectively, whose structures are confirmed by ${ }^{1} \mathrm{H}$ NMR. Meanwhile the molecular weight of sPCL-PEG-GA can be altered by the reaction parameter. The work explored a new synthesis route of star polymer with liver targetability. The star-shaped polymer is expected to be an efficient drug carrier, whose application in pharmaceutics will be studied in subsequent work.

\section{Abbreviation}

sPCL-b-PEG-GA: Star-shaped poly $(\varepsilon-$ caprolactone)-Poly(ethylene glycol) block copolymer modified by glycyrrhetinic acid

TsCl: p-Toluenesulfonyl chloride
EDC:

DMAP:

NHS:

GA:

1-(3-Dimethylaminopropyl)-3ethylcarbodiimide

$\mathrm{NH}_{2}$-PEG-GA: Amine-terminated polyethylene glycol modified by glycyrrhetinic acid

sTO-PEG-OTs: Bistosylation polyethylene glycol sPCL-OH: Star-shaped polycaprolactone terminated with hydroxyl group

sPCL-COOH: Star-shaped polycaprolactone

PTOL: $\quad$ Pentaerythritol

CL: $\quad$ Caprolactone

PEG: Polyethylene glycol. 


\section{Conflict of Interests}

The authors declare that they have no conflict of interests regarding the publication of this paper.

\section{Acknowledgments}

This work was financially supported by the Tianjin City High School Science \& Technology Fund Planning Project (20090227), National Natural Science Foundation of China (81202921), the Fiftieth Batch China Postdoctoral Science Foundation (92388), and National Training Programs of Innovation and Entrepreneurship for Undergraduates (201310063012).

\section{References}

[1] J. Cheng, J.-X. Ding, Y.-C. Wang, and J. Wang, "Synthesis and characterization of star-shaped block copolymer of poly( $\varepsilon$-caprolactone) and poly(ethyl ethylene phosphate) as drug carrier," Polymer, vol. 49, no. 22, pp. 4784-4790, 2008.

[2] Q. X. Yu, G. M. Zhu, G. Z. Liang, Z. G. Du, and Z. H. Gong, "Synthesis, properties and applications of poly $(\varepsilon$ caprolactone)," Polymeric Materials Science \& Engineering, vol. 5, pp. 37-40, 2004.

[3] S.-P. Zhao, M.-J. Cao, L.-Y. Li, and W.-L. Xu, "Synthesis and properties of photopolymerized $\mathrm{pH}$-sensitive hydrogels of methacrylic acid and biodegradable PEG-b-PCL macromer," Iranian Polymer Journal (English Edition), vol. 20, no. 4, pp. 329340, 2011.

[4] C. He, J. Sun, C. Deng et al., "Study of the synthesis, crystallization, and morphology of poly(ethylene glycol) - poly $(\varepsilon$ caprolactone) diblock copolymers," Biomacromolecules, vol. 5, no. 5, pp. 2042-2047, 2004.

[5] A. S. Mikhail and C. Allen, "Poly(ethylene glycol)-b-poly( $\varepsilon$ caprolactone) micelles containing chemically conjugated and physically entrapped docetaxel: synthesis, characterization, and the influence of the drug on micelle morphology," Biomacromolecules, vol. 11, no. 5, pp. 1273-1280, 2010.

[6] G. L. Ma, S. X. Zhao, X. Jin, M. M. Chen, Z. P. Zhang, and C. X. Song, "Folate-conjugated micelles based on star-shaped PLGAPEG-NH $\mathrm{N}_{2}$ copolymers as novel tumor-targeted nanocarriers," Chemical Journla of Chinese Universities, vol. 8, pp. 1854-1859, 2012.

[7] C. Ouyang, Q. Liu, S. Zhao, G. Ma, Z. Zhang, and C. Song, "Synthesis and characterization of star-shaped poly (lactide-coglycolide) and its drug-loaded microspheres," Polymer Bulletin, vol. 68, no. 1, pp. 27-36, 2012.

[8] J. Cheng, J.-X. Ding, Y.-C. Wang, and J. Wang, "Synthesis and characterization of star-shaped block copolymer of poly( $\varepsilon$-caprolactone) and poly(ethyl ethylene phosphate) as drug carrier," Polymer, vol. 49, no. 22, pp. 4784-4790, 2008.

[9] S.-J. Mao, Y.-Q. Bi, J. Hui, D.-P. Wei, H. Ru, and S.-X. Hou, "Preparation, characterization and uptake by primary cultured rat hepatocytes of liposomes surface-modified with glycyrrhetinic acid," Pharmazie, vol. 62, no. 8, pp. 614-619, 2007.

[10] Z. Y. He, X. Zheng, X. H. Wu et al., "Development of glycyrrhetinic acid-modified stealth cationic liposomes for gene delivery," International Journal of Pharmaceutics, vol. 397, no. 12, pp. 147-154, 2010. 

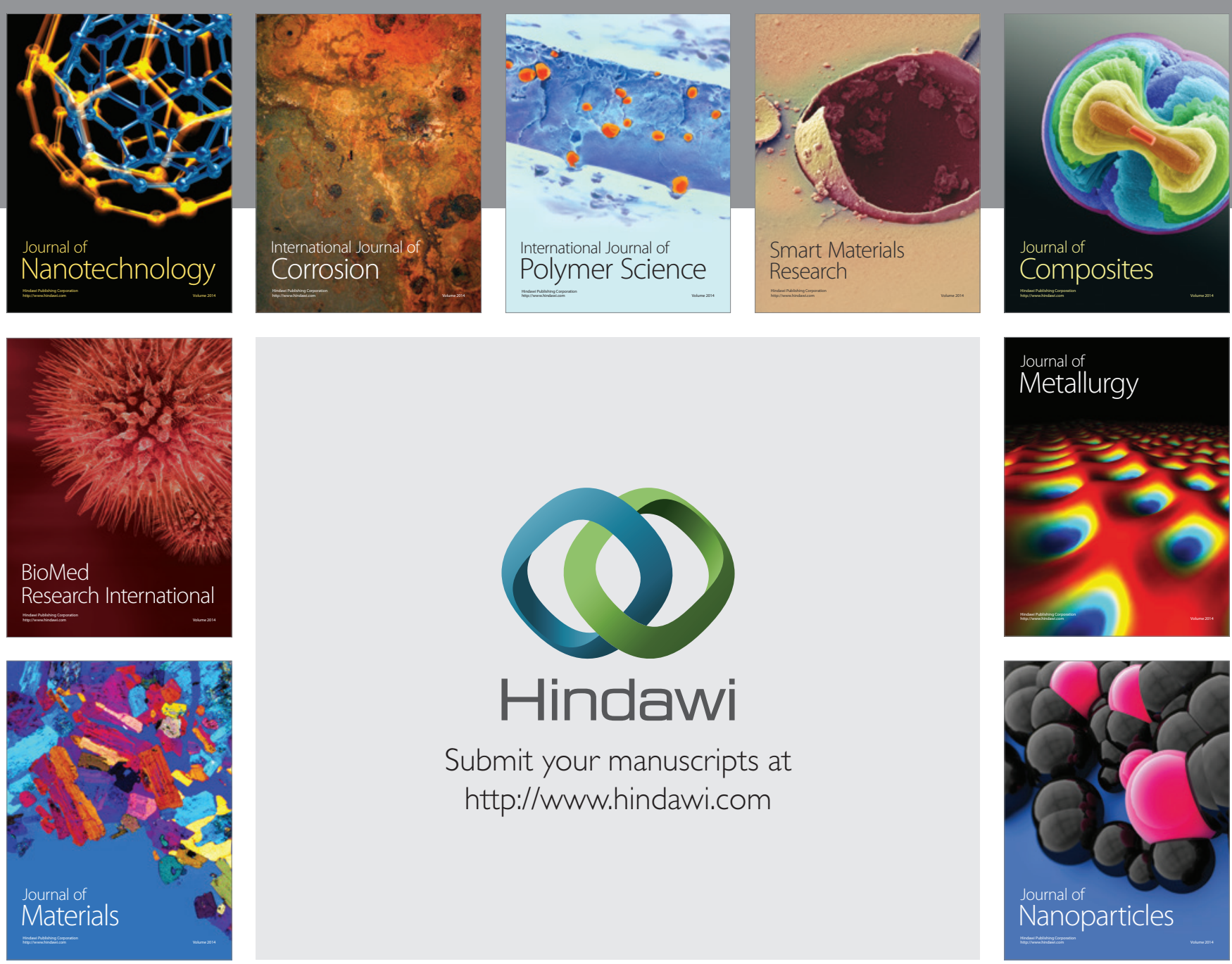

Submit your manuscripts at http://www.hindawi.com
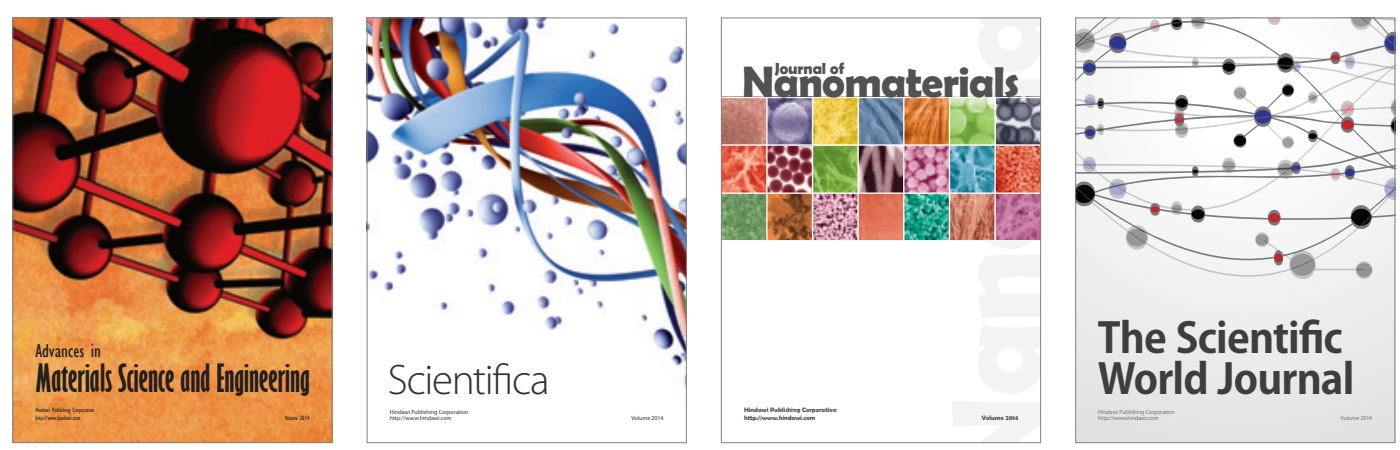

\section{The Scientific World Journal}
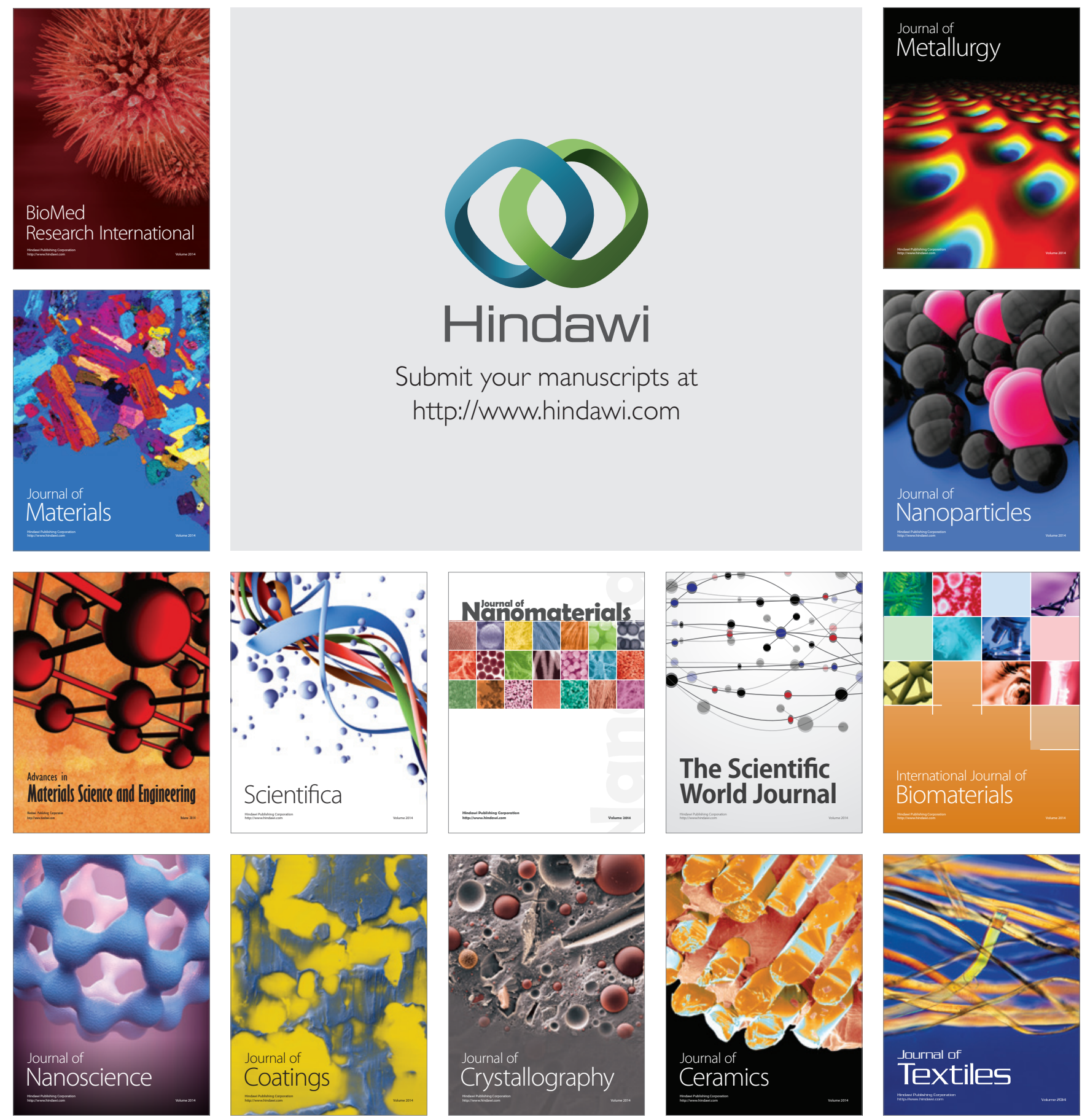